\title{
Cytochemistry and Polarization Microscopy of Amphibian Sperm Cell Nuclei Presumed to Differ in Basic Protein Composition
}

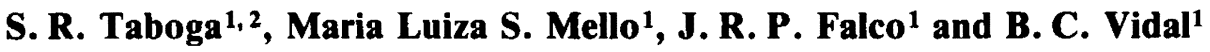 \\ 'Department of Cell Biology, Institute of Biology, UNICAMP, 13083-970 Campinas, SP, Brazil and 'Department of \\ Biology, IBILCE/UNESP, 15054-000 São José do Rio Preto, SP, Brazil
}

Received for publication July 4, 1996

\begin{abstract}
The pattern of availability of free DNA phosphates, and the kind of DNA-protein complex arrangement, both induced by nuclear basic proteins, and the richness in arginine residues in these proteins were investigated cytochemically and cytophysically in spermatozoa of the South-American Hylidae species, Hyla fuscovaria and Hyla biobeba. The aim was to demonstrate differences at the level of sperm histones in two species of $H y l a$ until recently considered to be congeneric. The results indicated differences in the spermatozoal nuclear basic proteins and DNA-protein complexes when the two species were compared. The spermatozoa of Hyla biobeba were assumed to
\end{abstract}

be likely to contain a Bloch's "type 3" protein type (intermediate sperm basic protein), similarly to Hyla species of North and Central America. On the other hand, the data obtained for the spermatozoa of Hyla fuscovaria indicated that they contain a protamine or protamine-like protein, differing from Hyla biobeba and Hyla species of North and Central America. It is suggested that the differences reported here may be genusspecific, since Hyla fuscovaria has recently been reclassified as Scinax fuscovaria based on parameters other than sperm histone types. These findings are in agreement with the general view of a wide variability in sperm nuclear proteins in the Anura group.

Key words: Spermatozoa, Nuclear proteins, Amphibia, Cytochemistry, Polarization microscopy

\section{Introduction}

Spermatozoa are grouped into many dissimilar classes, considering the protein components of their DNAprotein complexes. In 1969 Bloch [2] suggested a classification into five classes for the sperm nuclear proteins. These classes have been named (1) true protamines or "salmon-type" protamines (arginine-rich; no lysine); (2) protamine-like or keratinous protamines (arginine-rich, little or no lysine, but oxidized cysteine being also present); (3) intermediate sperm basic proteins (containing histidine and/or lysine in addition to arginine); (4) somatic-like histones or "Rana type" (lysine-rich); and (5) nonbasic or "crab type" (no histones or protamines). Additional changes have later been proposed for Bloch's classification, taking into account relationships between some of the categories and subtle differences between them $[20,22]$.

Correspondence to: Dr. Maria Luiza S. Mello, Department of Cell Biology, Institute of Biology, UNICAMP, 13083-970 Campinas, SP, Brazil.
As regards the spermatozoa of the amphibian group, a range of very different nucleoprotein types has been reported cytochemically and by electrophoresis $[4,5,11$, $13,21,22]$. In newts, the nuclear basic proteins of the spermatozoa are of the protamine type $[6,21]$. Frogs apparently have typical somatic histones with additional protamines or other basic proteins [22]. Rana spermatozoa contain a sperm-specific $\mathrm{H} 1$ histone (very lysinerich typical histone, Bloch's "type 4" class) [10]. A nuclear basic protein which comigrated with authentic protamine has been found by gel electrophoresis for Bufo americanus, but it was later shown to contain lysine and histidine $[5,10]$. The electrophoretic migrating patterns of the basic nuclear proteins in Xenopus sperm cells have been found to vary with species $[11,13]$. While the spermatozoa of Hyla regilla, Hyla gratiosa and Hyla versicolor have been pointed out to contain intermediate basic proteins (Bloch's "type 3 " class) $[4,5,11]$, the sperm cells of Hyla ranki, a Brazilian Hylidae species, studied by cytochemical procedures, have been proposed to contain a protamine-like protein probably in association with 
somatic histones [23].

Since the above-mentioned sperm cell protein categories are supposed to differently associate with DNA, it is expected (and even proved for the materials analyzed thus far) that the number and proximity of DNA phosphates available for cationic dye binding should differ in cases of different basic proteins being present $[8,12,14$, $17,18]$. Consequently, if toluidine blue (TB) molecules are furnished for electrostatic binding to free DNA phosphates, different spectral patterns of basophila, even under competitive inorganic cation conditions [26], should be exhibited by sperm cells containing different DNA-protein complexes. Patterns of optical anisotropy, namely dispersion of birefringence (birefringence sign varying as a function of the wavelength of the incident light), could also vary in these TB-stained materials, since they are a function of the oriented arrangement of the DNA bases plus the oriented piling of the dye molecules bound to available DNA phosphates unattached to protein amino groups $[15,17,18,26]$.

When examining TB-stained testis preparations of two South American Hylidae species other than Hyla ranki, but until recently considered to belong to the same Hyla genus, the patterns of spermatozoal nuclear basophilia have been found to differ visually from each other. This led us to suspect that differences in basic proteins making complexes with the DNA could be involved in sperm cells of Hyla congeneric species, as is the case for congeneric species of Xenopus [13]. In fact, the electrophoretic pattern of testis-specific histones has been reported not to differ in the congeneric species of Hyla studied by Kasinsky and co-workers [11], although differences at a greater resolution level have not been discarded. Furthermore, no data have been established for South-American species other than Hyla ranki.

The present study thus aimed at comparing the response to TB staining, and the accompanying optical anisotropy characteristics, in spermatozoal nuclei of $\mathrm{Hyla}$ fuscovaria and Hyla biobeba. The objective was to better differentiate the sperm cell nuclei of these species and to establish their nucleoprotein properties at the cytochemical level. Spermatozoa with chromatin proteins classified as belonging to the classes of keratinous protamines and somatic-like $\mathrm{H} 1$ histones $[2,17,22]$ were also analyzed as standards. Published data for complexes of true protamine-DNA and $\mathrm{H} 1$ histone-DNA complexes in vitro [26] were additionally considered for comparative purposes in the Discussion section.

Preliminary data on this subject have been briefly communicated in the 7th International Symposium on Spermatology at Cairns [24].

\section{Materials and Methods}

Formalin-fixed testes of Hyla fuscovaria (=Scinax fuscovaria) and Hyla biobeba (Amphibia, Hylidae), Mus musculus and Rattus norvegicus (Mammalia, Rodentiae), and smears of ejaculated sperm cells of Apis mellifera (Hymenoptera, Apoidea) were used. Smears and organs from at least 4 specimens of each species were employed.

The testes and sperm cell smears were fixed for $24 \mathrm{hr}$ and $1 \mathrm{hr}$, respectively. The organs were embedded in Paraplast-plus and sectioned at $8 \mu \mathrm{m}$ thickness. Both sections and smears were treated with a $0.025 \%$ toluidine blue (TB) solution at $\mathrm{pH} 4.0$. Staining was also carried out with solutions of this dye prepared by the addition of various concentrations $(0.01 \mathrm{M}$ through $0.20 \mathrm{M})$ of $\mathrm{MgCl}_{2}$ and $\mathrm{CaCl}_{2}$, in order to establish the critical electrolyte concentration $\left(=\mathrm{CEC}\right.$, concentration of $\mathrm{Mg}^{2+}$ or $\mathrm{Ca}^{2+}$ at which the nuclear metachromasy appears to be abolished [26]. The final pH of these solutions was not adjusted. The preparations were then rapidly (5s) rinsed in distilled water, air-dried, cleared in xylene, and mounted in Eukitte.

The fast green staining procedure preceded by deamination, as described by Bloch and Hew [3], was used for the investigation of richness in arginine residues in part of the preparations.

Observations were carried out under polarized and unpolarized light conditions. Wavelengths of absorption peaks were determined after the evaluation of spectral absorption curves for the TB-stained preparations under unpolarized light conditions with Zeiss equipment (EMI 6256 photomultiplier, photometer 01, Planapo 100/1.25 objective, optovar 2, measuring diaphragm diameter of $0.25 \mathrm{~mm}$, Epiplan 16/0.30 condenser). Wavelengths from 430 to $680 \mathrm{~nm}$ were provided by a Schott monochromator filter ruler. Since visual observations have proven efficient to discriminate the green color corresponding to the microspectrophotometrically established CEC point for the DNA under $\mathrm{TB} / \mathrm{Mg}^{2+}$ competitive staining conditions [26], detection of the wavelength of the absorption peaks for the sperm cells in this case was not deemed necessary.

The dispersion of birefringence in TB-stained preparations was investigated with a Zeiss Pol-photomicroscope by determining the sign of the optical retardations at different $\lambda$ provided by Schott interferential filters, with a Sénarmont's rotatory analyzer and Bräce-Kóhler's rotatory compensators.

\section{Results}

Figure 1 (a-e) shows aspects of the TB staning in Hyla fuscovaria, Hyla biobeba and Apis mellifera sperm cells under unpolarized and polarized light conditions.

The absorption peak of the spectral absorption curves of the sperm cell nuclei in Hyla fuscovaria was found to be positioned close to that exhibited by Mus musculus and Rattus norvegicus, whereas that of Hyla biobeba was slightly higher than that for Apis mellifera (Table 1).

Since the spermatozoa of Hyla fuscovaria, Mus musculus and Rattus norvegicus were devoid of nuclear metachromasy under TB staining in the absence of competitive $\mathrm{Mg}^{2+}$ and $\mathrm{Ca}^{2+}$ ions, CEC could only be detected 

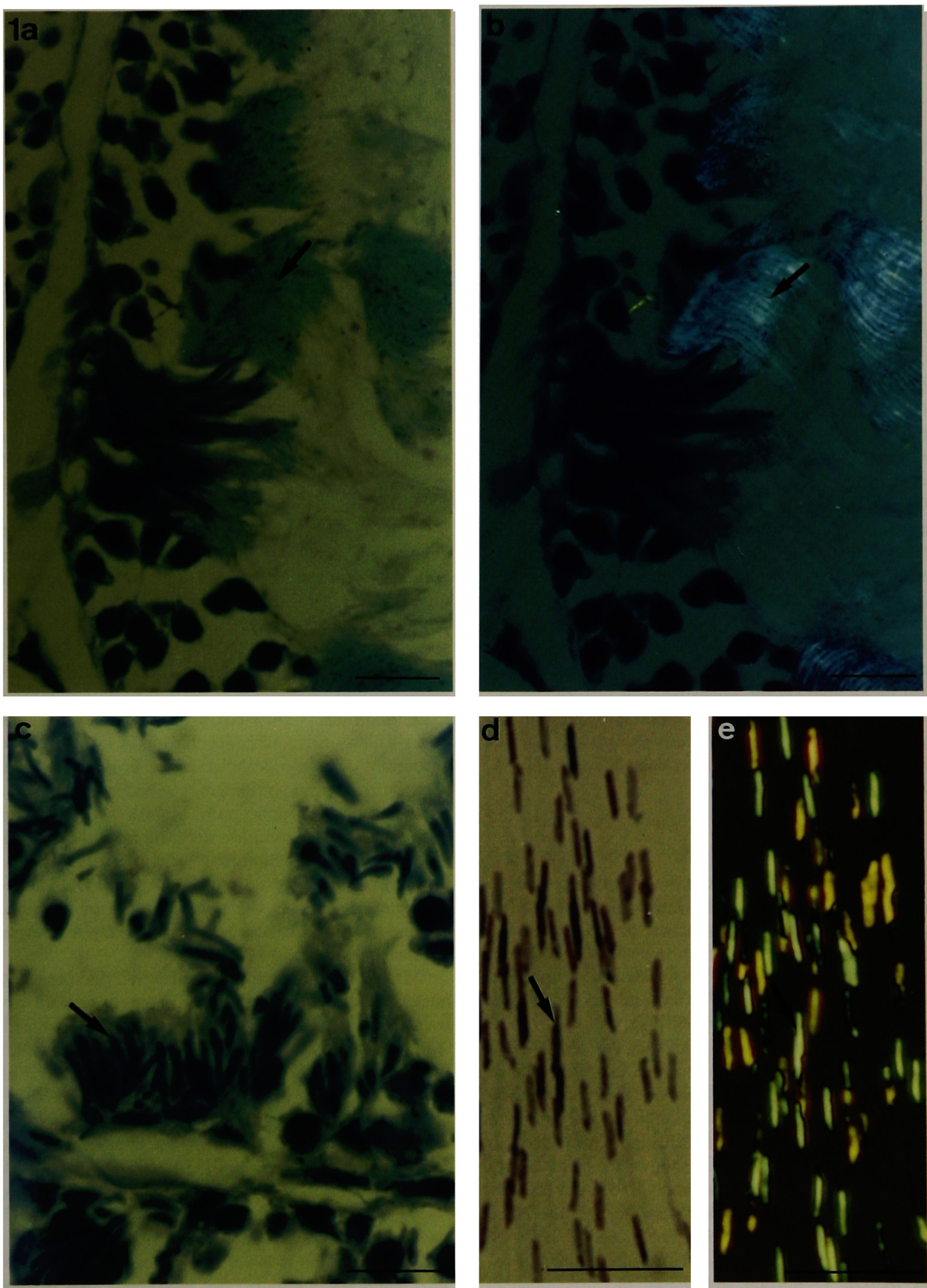

Fig. 1. TB-stained spermatozoa (arrows) of Hyla fuscovaria (a, b), Hyla biobeba (c) and Apis mellifera (d, e) as seen with unpolarized (a, c, d) and polarized (b, e) light. Bar $=30 \mu \mathrm{m}$. 
Table 1. Cytochemistry and polarized light data for sperm cell nuclei

\begin{tabular}{lcccc}
\hline Species & \multicolumn{3}{c}{ TB staining } & FG staining \\
\cline { 2 - 4 } & $\begin{array}{l}\text { absorption } \\
\text { peak }(\lambda \text { in } \mathrm{nm})\end{array}$ & birefringence & $\begin{array}{l}\mathrm{CEC} \text { value } \\
\text { in } \mathrm{M} \text { of } \\
\mathrm{Mg}^{2+} / \mathrm{Ca}^{2+}\end{array}$ & $\begin{array}{l}\text { after } \\
\text { deamination }\end{array}$ \\
\hline Hyla fuscovaria & $610-25$ & $\mathrm{DB}$ & $\mathrm{b}$ & + \\
Hyla biobeba & 580 & $\mathrm{a}$ & 0.10 & + \\
Mus musculus & $>600$ & $\mathrm{DB}$ & $\mathrm{b}$ & + \\
Rattus norvegicus & $>600$ & $\mathrm{DB}$ & $\mathrm{b}$ & + \\
Apis mellifera & 570 & $\mathrm{ADB}$ & 0.08 & - \\
\hline
\end{tabular}

a, non-detectable; ADB, anomalous dispersion of birefringence; $b$, non-metachromatic in the absence of competitive ions; $\mathrm{CEC}$, critical electrolyte concentration; $\mathrm{DB}$, normal dispersion of birefringence; FG, fast green; TB, toluidine blue; -, negative

for the sperm cells of Hyla biobeba and Apis mellifera. The CEC value for Hyla biobeba was found to be slightly higher than that of Apis mellifera (Table 1). The CEC values were not affected by the competitive inorganic cation type $\left(\mathrm{Mg}^{2+}\right.$ or $\left.\mathrm{Ca}^{2+}\right)$.

Optical anisotropy after TB staining was exhibited by the sperm cell nuclei of all the species studied here, with the exception of Hyla biobeba (Table 1). The phenomenon of anomalous dispersion of birefringence, i.e., optical retardations of negative sign for light of wavelengths higher than $546 \mathrm{~nm}$ and positive for light of wavelengths under $519 \mathrm{~nm}$ was detected only in the honey bee. The other species exhibited negative retardations all along the $\lambda$ spectral range used (normal dispersion of birefringence).

With the exception of the spermatozoa of Apis mellifera, those for the other species exhibited a positive response to fast green staining after deamination (Table 1; Fig. 2a-f).

\section{Discussion}

The spectral characteristics of the basophilia exhibited by the sperm cell nuclei here analyzed indicate that a few DNA phosphates remain unattached to protein amino groups in Hyla fuscovaria (absorption peak at $\lambda>600 \mathrm{~nm}$ ), while a reasonable number of DNA phosphates unbound to protein and suitable to bind TB molecules occur in Hyla biobeba (absorption peak at $\lambda=580 \mathrm{~nm}$ ).

A metachromatic staining like that verified in Hyla biobeba spermatozoal nuclei also occurs in Apis mellifera sperm cells as well as in DNA-very lysine-rich histone complexes in vitro [26] and in most somatic cell nuclei in situ [15]. On the other hand, no metachromatic response was detectable in Hyla fuscovaria, similar to observations reported for Hyla ranki [23] and also for DNA-protamine or for DNA-keratinous protamine complexes like those found in mammals and some insects $[12,14,18,26]$.

As regards the optical anisotropy data, the phenomenon of DB (=normal dispersion of birefringence, characterized by absence of changes in birefringence sign along the spectral range considered), reinforcing the DNA anisotropy, was demonstrated for the TB-stained sperm cell nuclei of Hyla fuscovaria, which did not exhibit metachromasy. The phenomenon of DB accompanied by metachromasy absence is typical of a tightly packed DNAprotamine complex $[25,26]$ or even complexes of DNAkeratinous protamines [18].

On the other hand, the absence of birefringence in the TB-stained sperm cell nuclei of Hyla biobeba contrasts with the occurrence of ADB (= anomalous dispersion of birefringence, characterized by presence of at least one point of change in birefringence sign) in Apis mellifera spermatozoal nuclei and DNA-lysine-rich histone complexes in vitro, despite the fact that all of them exhibited a metachromatic staining $[17,26]$. It may thus mean that the arrangement of the DNA-protein complex presumed to occur with an oriented conformation in the spermatozoal chromatin of Hyla biobeba is masked at the level of chromatin supraorganization. Consequently, an apparent disordered array may abolish the anisotropical phenomena of this complex, differing from the situation in Apis mellifera spermatozoa and in DNA-lysine-rich histone complexes $[17,26]$ which reflects the DNA stereoarrangement itself plus the oriented array of a significant amount of dye molecules bound to free DNA phosphates unattached to protein $[17,18]$.

These facts are highly indicative that the spermatozoal nuclei of Hyla biobeba do not properly contain a very lysine-rich histone (H1 category) such as that assumed for Apis mellifera $[2,17]$, but do most probably contain a Bloch's "type 3 " protein. In fact, data on the fast green staining response after deamination revealed that the nuclear basic protein of the sperm cells of Hyla biobeba, differing from that of Apis mellifera, contains a significant amount of arginine residues [3, 4]. In favor of the same idea is also the finding that the availability of the spermatozoal DNA phosphates revealed on the basis of the wavelength of the spectral absorption peaks of the TB nuclear basophilia is lower in Hyla biobeba compared to Apis mellifera. Finally, the hypothesis that a Bloch's "type 3" protein occurs in Hyla biobeba would be in agreement with cytochemical and biochemical data for con- 


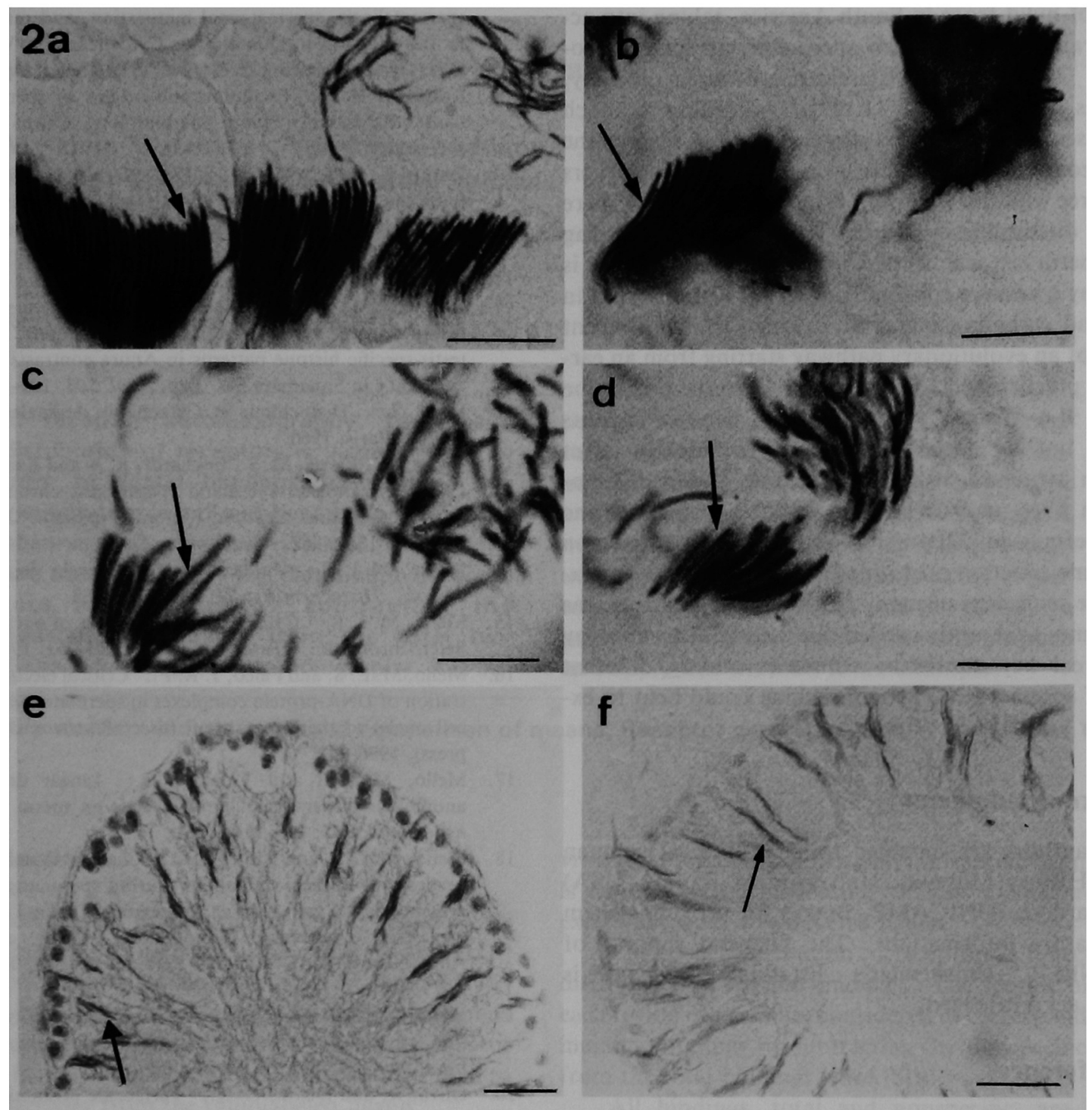

Fig. 2. Fast green staining preceded (b, d, f) or not (a, c, e) by deamination in spermatozoa (arrows) of Hyla fuscovaria (a, b), Hyla biobeba (c, d) and Rattus norvegicus (e, f). $\mathrm{Bar}=30 \mu \mathrm{m}$.

generic species of Hyla of North and Central America [4, $5,11]$.

On the other hand, considering that Hyla fuscovaria as well as Hyla ranki have been recently proposed for reclassification into the Scinax genus [7], it may occur that species of this genus could differ from Hyla also by containing a protamine or a protamine-like protein instead of a Bloch's "type 3 " protein as part of the DNA-protein complex of the sperm cells. Work in progress by M.L.S. Mello and A. Cardoso (UNICAMP, Brazil) is revealing that some other congeneric species of Scinax exhibit the same cytochemical responses here reported for Hyla (=Scinax) fuscovaria .

Considering CEC as a function of free DNA phosphates available for the dye $/ \mathrm{Mg}^{2+} / \mathrm{Ca}^{2+}$ binding competitive action [26], more $\mathrm{Mg}^{2+} / \mathrm{Ca}^{2+}$ cations are required for CEC to be attained in the chromatin of the spermatozoa of Hyla biobeba in comparison to Apis mellifera. Since higher CEC values have been reported for tightly packed chromatin types [16,19], it is thus possible that the packing state of the spermatozoal chromatin of Hyla biobeba should be more condensed than that of Apis mellifera. Although CEC data cannot be established for the spermatozoa of Hyla (=Scinax) fuscovaria, the other data for their DNA-protein complex type are suffcient to suggest that the packing state of the chromosomal chromatin of this species is more condensed than that of Hyla biobeba.

The finding of large differences in basic nuclear protein types in the sperm cells of the species here studied is in agreement with the wide variability in protein composition in the Anura group [10, 11, 22] and the report of a great 
diversity of hylid frogs in South America, taking into account parameters other than spermatozoal nuclear proteins [7]. The biological significance of such diversity, however is still unclear $[9,11,22]$. According to Bloch [2], there seems to be no evolutionary trend as regards the spermatozoal nuclear proteins. Kasinsky and co-workers [11] disagree with this hypothesis, by contending that there is a trend discernible in the vertebrates when considering that the sperm histone diversity in fishes and amphibians is replaced by a relative constancy of sperm histone types in reptiles and eutherian mammals. There is also a recent proposal of an evolutionary pathway starting from an early histone precursor (H1 histone) leading to the protamine types $[1,9]$. When considering these histone variants it should not be neglected that they differently affect chromatin structure at the nucleosome and/or $30-\mathrm{nm}$ chromatin fiber, and/or packing of these fibers into the mature sperm head [22] possibly better fitting spermatozoa to overcome selection pressures [20]. Perhaps determination of the sequences of many spermatozoal basic nuclear protein genes as recently carried out with PCR technology could reveal key consensus sequences among different groups of spermatozoal histones which could help to explain their variation in phylogeny [20].

\section{Acknowledgments}

The authors are indebted to Drs. W.E. Duellman (Natural History Museum, University of Kansas, USA) and A. Cardoso (UNICAMP, Brazil) for providing them with literature information. The financial support of FUNDUNESP (Universidade Estadual Paulista) is gratefully acknowledged.

\section{References}

1. Ausio, J.: Histone $\mathrm{H} 1$ and the evolution of the nuclear spermspecific proteins. 7th Intern. Symp. Spermatology, Cairns 1994. Abstracts 5.37, 1994.

2. Bloch, D. P.: A catalog of sperm histones. Genetics 61 (Suppl.); 93-111, 1969.

3. Bloch, D. P. and Hew, H. Y. C.: Schedule of spermatogenesis in the pulmonate snail Helix aspersa, with special reference to histone transition. J. Biophys. Biochem. Cytol. 7; 515-532, 1960.

4. Bols, N. C. and Kasinsky, H. E.: Basic protein composition of anuran sperm: a cytochemical study. Can. J. Zool. 50; 171$177,1972$.

5. Bols, N. C. and Kasinsky, H. E.: An electrophoretic comparison of histones in anuran testes. Can. J. Zool. 51; 203208, 1973.

6. Bols, N. C., Byrd Jr., E.W. and Kasinsky, H. E.: On the diversity of sperm histones in the vertebrates. I. Changes in basic proteins during spermiogenesis in the newt Notophthalmus viridescens. Differentiation 7; 31-38, 1976.

7. Duellman, W. E. and Wiens, J. J.: The status of the hylid frog genus Ololygon and the recognition of Scinax Wagler, 1830. Occas. Pap. Mus. Nat. Hist. Univ. Kansas 151; 1-23, 1992.

8. Gledhill, B. L.: Changes in nuclear stainability associated with spermateliosis, spermatozoal maturation, and male infertility. In Introduction to Quantitative Cytochemistry, Vol. 2, ed. by G. L. Wied, Academic Press, New York, 1970, pp. 125-131.

9. Kasinsky, H. E.: Evolution and origins of sperm basic proteins. 7th Intern. Symp. Spermatology, Cairns 1994. Abstracts; 5.40, 1994.

10. Kasinsky, H.E., Huang, S. Y., Mann, M., Roca, J. and Subirana, J.A.: On the diversity of sperm histones in the vertebrates. IV. Cytochemical and amino acid analysis in Anura. J. Exp. Zool. 234; 33-46, 1985.

11. Kasinsky, H. E., Huang, S. Y., Kwauk, S., Mann, M., Sweeney, M. A. J. and Yee, B.: On the diversity of sperm histones in the vertebrates. III. Electrophoretic variability of testis-specific histone patterns in Anura contrasts with relative constancy in Squamata. J. Exp. Zool. 203; 109-126, 1978.

12. Lison, L.: Histochimie et Cytochimie Animales. GauthierVillars, Paris, 1960.

13. Mann, M., Risley, M. S., Eckhardt, R. A and Kasinsky, H. E.: Characterization of spermatid/sperm basic chromosomal proteins in the genus Xenopus (Anura, Pipidae). J. Exp. Zool. 222; 173-186, 1982.

14. Mello, M. L.S.: Induced metachromasia in bull spermatozoa. Histochemistry 74; 387-392, 1982.

15. Mello, M. L. S.: Cytochemical properties of euchromatin and heterochromatin. Histochem. J. 15; 739-751, 1983.

16. Mello, M. L. S. and Falco, J. R. P.: Critical electrolyte concentration of DNA-protein complexes in spermatozoal and somatic cell nuclei of the honey bee. Insect Biochem. Mol. Biol. (in press), 1996.

17. Mello, M. L. S. and Vidal, B. C.: Linear dichroism and anomalous dispersion of birefringence on sperm heads. Acta histochemica 45; 109-114, 1973.

18. Mello, M. L. S. and Vidal, B. C.: Changes in anisotropic properties and nuclear stainability during spermatogenesis in the grasshopper, Staurorhectus longicornis Giglio-Toss. In Advances in Invertebrate Reproduction. Vol. 1, ed. by K. G. Adiyodi and R. G. Adiyodi Peralam-Kenoth, Kerala, 1977, pp. 75-83.

19. Mello, M. L. S. and Vidal, B. C.: Critical electrolyte concentration of the heterochromatin and euchromatin of Triatoma infestans. Cytobios 59; 87-93, 1989.

20. Oliva, R. and Dixon, G. H.: Vertebrate protamine genes and the histone-to-protamine replacement reaction. Progr. Nucl. Acid Res. Mol. Biol 40; 25-94, 1991.

21. Picheral, B.: Nature et évolution des protéines basiques au cours de la spermiogenèse chez Pleurodeles waltii Michah., amphibien urodèle. Histochemie 23; 189-206, 1970.

22. Poccia, D.: Remodeling of nucleoproteins during gametogenesis, fertilization, and early development. Int. Rev. Cytol. $105 ; 1-65,1986$.

23. Taboga, S. R. and Dolder, H.: Basic nuclear protein substitution during spermiogenesis in Hyla ranki (Amphibia, Anura, Hylidae). Ciênc. Cult., São Paulo 46; 161-163, 1994.

24. Taboga, S. R., Falco, J. R. P., Vidal, B. C. and Mello, M. L.S.: Cytochemistry and polarization microscopy of sperm cell nuclei presumed to differ in basic protein composition. 7th International Symposium on Spermatology, Cairns 1994. Abstracts; 2.4-2.5, 1994.

25. Vidal, B. C.: The effect of clupein on anisotropy and basophilia of polytene chromosomes. Histochemistry 60; 309316, 1979.

26. Vidal, B. C. and Mello, M. L. S.: Critical electrolyte concentration of DNA and nucleoprotein complexes in vitro. Acta Histochem. Cytochem. 22; 471-478, 1989. 